\title{
Effect of Cholera Toxin on Insulin Release in Monolayer Cultures of the Endocrine Pancreas
}

\author{
C. B. Wollheim, B. Blondel, and G.W.G. Sharp \\ Institut de Biochimie Clinique and Institut d'Histologie, University of Geneva, Geneva, Switzerland
}

Received: May 20, 1974 and in revised form: August 5, 1974

\begin{abstract}
Summary. The effect of cholera toxin on insulin release by monolayer cultures of endocrine pancreas has been studied. The toxin has a marked stimulatory effect upon insulin release at concentrations as low as $10^{-10} \mathrm{M}$. The toxin had a small effect at low glucose concentrations, but was strongly stimulatory at high glucose concentrations and in the presence of arginine. Its effect could be detected within 30 min of application and only two minutes'
\end{abstract}

exposure to the toxin was required for it to subsequently stimulate release. In comparative studies on insulin release the toxin was equal to, or slightly more potent than, $1.5 \mu \mathrm{M}$ glucagon and significantly more potent than cyclic AMP $(10 \mathrm{mM})$ or theophylline $(5 \mathrm{mM})$.

Key words: Insulin release, cholera toxin, cyclic AMP, monolayer culture.
Diarrhoea in patients with cholera is caused by an exoenterotoxin produced by Vibrio cholerae [1]. The toxin, a protein of molecular weight approximately 84000 [2], stimulates the movement of ions from blood to the lumen of the intestine and a concomitant osmotic equivalent of water [3]. Thus the secretory function of the intestine exceeds the reabsorptive capacity and diarrhoea results. The toxin produces these effects by stimulating adenylate cyclase in the epithelial cells of the small intestine $[4-6]$. In the natural disease the toxin is restricted to the intestine and only the intestinal cells show an increase in adenylate cyclase activity. In experimental situations, however, cholera toxin can be applied to a variety of cell types. In most cells tested thus far effects of the toxin due to stimulation of adenylate cyclase and increased intracellular cyclic AMP concentrations have been detected. For example, cholera toxin has been shown to act on fat cells [7], platelets [8], liver [9], leucocytes [10], and adrenal cortex $[11,12]$. Thus the toxin may be a universal stimulator of adenylate cyclase.

As cyclic AMP has important effects in enhancing insulin release from the B-cells of pancreatic islets [13-16] it was decided to explore the use of cholera toxin as a tool for the study of insulin release. The monolayer culture of newborn rat pancreas was used for the study because of the ease of access of the toxin to the cells.

\section{Methods}

The culture technique has been described in detail previously $[17,18]$. In brief, about one hundred pancreata from 1-3 day old Wistar rats were excised under sterile conditions and cut into pieces $1-2 \mathrm{~mm}$ in diameter. The pancreatic pieces were submitted to 10 consecutive treatments with a mixture of trypsin and collagenase ( $\mathrm{pH} 7.5$ at $\left.37^{\circ} \mathrm{C}\right)$.
The 3-4 initial supernatants were discarded and the following supernatants, containing isolated cells, were diluted in ice-cold culture medium (TCMI 99) containing $10 \%$ calf serum, $16.7 \mathrm{mM}$ glucose, $14 \mathrm{mM}$ sodium-bicarbonate and $400 \mathrm{U} / \mathrm{ml}$ sodium penicillin. The pooled supernatants were centrifuged twice at $150 \times \mathrm{g}$ and each time the packed cells were resuspended gently in fresh culture medium. The cell suspensions were pooled and plated into about 40 plastic Petri dishes, yielding about 700000 cells per $\mathrm{cm}^{3} .14 \mathrm{hrs}$ after plating, at a time when most fibroblastoid cells had attached to the bottom of the Petri dish, in contrast to the epithelioid cells, the supernatants were again decanted into Petri dishes. 44 hrs after the original plating, during which time the glucose concentration of the culture medium was kept at $16.7 \mathrm{mM}$, the cells were washed carefully and fresh culture medium containing $5.6 \mathrm{mM}$ glucose was added. The cultures were maintained at $37^{\circ} \mathrm{C}$ and $\mathrm{pH} 7.40 \pm 0.05$ by varying the carbon dioxide concentration in the incubator. The experiments reported here were performed on the third day of culture. By this time the remaining exocrine cells in the culture are devoid of zymogen granules as evidenced by electron microscopy [19] and amylase was not detectable in the culture medium. Incubation experiments were carried out in Krebs-Ringer bicarbonate buffer, containing either $2.5 \mathrm{mM}$ or $1.0 \mathrm{mM} \mathrm{CaCl}$, $0.5 \%$ dialyzed bovine serum albumin, $250 \mathrm{KIU} / \mathrm{ml}$ Trasylol and the agents under study. Temperature and $\mathrm{pHI}$ during the incubations were identical to those during the culture period. $5 \mathrm{ml}$ of incubation medium were added to each Petri dish. In most experiments $0.5 \mathrm{ml}$ aliquots were taken at the time specified. Samples were immediately frozen and kept at $-20^{\circ} \mathrm{C}$ until assay. Immunoreactive insulin (IRI) was measured by the method of Herbert et al. [20], using rat insulin as standard, and guinea pig anti-porcine insulin serum. Cholera toxin was dissolved in sterile water and kept at $+4^{\circ}$. The toxin did not interfere 
with the immunoassay at the concentrations employed.

Petri dishes within a single culture preparation were paired for statistical analysis using Student's ttest. Where an occasional Petri dish was lost, its pair was deleted from the analysis. SEM in the figures represent the variation of the value for a single Petri dish and have no implication for the paired statistical treatment of the data.

The materials employed and their sources were as follows: trypsin (Difco Laboratories, Detroit, Michigan, USA), collagenase (Worthington Biochemical Corporation, Freehold, N.J., USA), medium TCMI 99 (Grand Island Biochemical Co., Grand Island, N.Y., USA), sodium penicillin G (Chas. Pfizer and Co. Inc., New York, N.Y., USA), $60 \mathrm{~mm}$ diameter plastic Petri dishes (Falcon Plastics Oxnard, California, USA), Trasylol (Bayer Pharma A.G., Zurich, Switzerland), bovine serum albumin (Behringwerke A.G., Marburg, FRG), glucose, arginine-monohydrochloride and theophylline (Merck A.G., Darmstadt, FRG) cyclic adenosime $3^{\prime}, 5^{\prime}$-monophosphate (Boehringer-Mannheim GmbH, Mannheim, FRG), rat insulin and porc-glucagon lot no. MC 6770 (gifts from Dr. J. Schlichtkrull, Novo Research Institute, Copenhagen, Denmark). Purified [21] cholera toxin, lot no. 0572 was kindly supplied by Dr. C. Miller, National Institute of Allergy and Infectious Diseases, NIH, Baltimore, Md., USA). The cholera toxin was prepared under contract for the National Institute of Allergy and Infectious Diseases (NIAID) by R.A. Finkelstein, Ph.D., The University of Texas Southwestern Medical School, Dallas, Texas, USA). Guinea pig anti-porcine insulin serum was generously provided by Dr. P. Wright, Indianapolis, Ind., USA).

\section{Results}

\section{a) Dose-Response Characteristics}

Cholera toxin was added to the incubation medium bathing the monolayer culture at three concentrations, $0.01,0.1$ and $1.0 \mu \mathrm{g} / \mathrm{ml}(0.01 \mu \mathrm{g} / \mathrm{ml}$ is equivalent to $1.2 \times 10^{-10} \mathrm{M}$ ). The results are shown in Fig. 1 . In the presence of $11 \mathrm{mM}$ glucose, the highest concentration of cholera toxin, $1 \mu \mathrm{g} / \mathrm{ml}$, stimulated insulin release to rates which were four times greater than the rate of glucose-induced release during the first hour. Thereafter, although the rate of release decreased, the rate was still higher than that achieved by glucose. At 0.1 $\mu \mathrm{g} / \mathrm{ml}$ the rate of release was double the glucose-induced rate at $1 \mathrm{~h}$, three times the rate at $2 \mathrm{~h}$ and the culture maintained a higher release rate to $4 \mathrm{~h}$. The lowest concentration of cholera toxin failed to stimulate insulin release during the first hour, but markedly stimulated release from $1-4 \mathrm{hrs}$, resulting in a near tripling of the insulin release rate during this time.

By contrast, cholera toxin failed in this small series of experiments to stimulate insulin release in the presence of a low concentration of glucose $(2.8 \mathrm{mM})$.
This confirms again that the effect of cyclic AMP on insulin release is a marked enhancement of the release induced by other stimulators rather than a major effect of cyclic AMP per se on the release mechanism. That cyclic AMP can elicit small effects on release at low glucose concentrations is shown by the results in section $\mathrm{b}$ ).
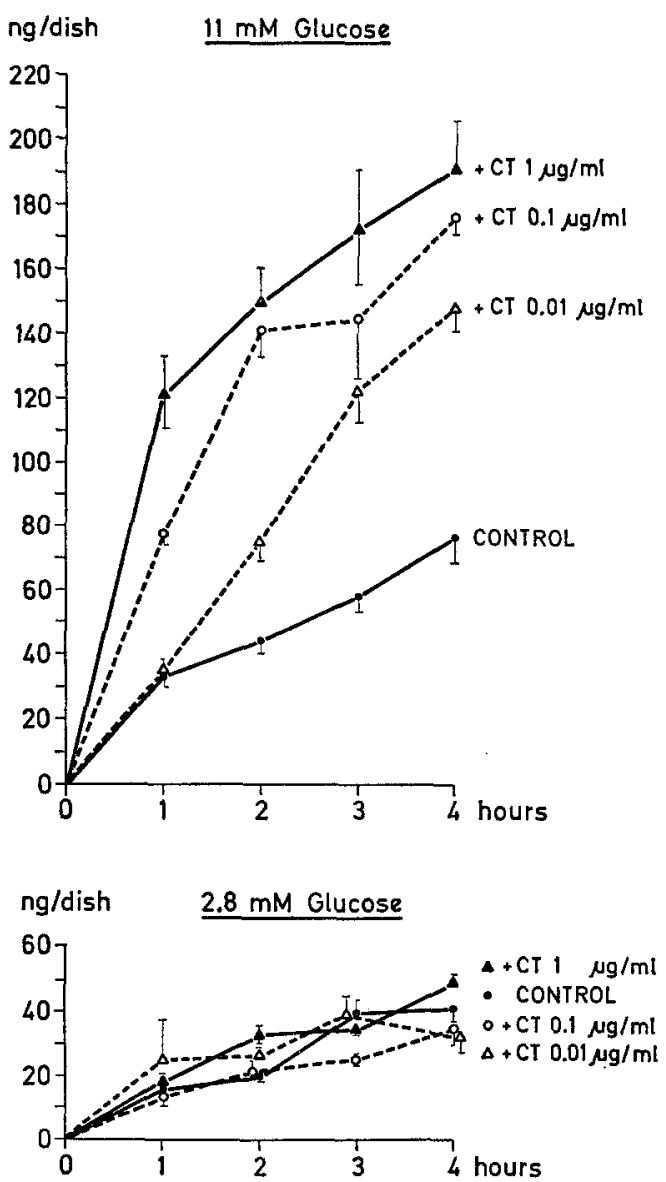

Fig. 1. Effect of different concentrations of cholera toxin on insulin release in the presence of glucose at $2.8 \mathrm{mM}$ (lower figure) and $11.0 \mathrm{mM}$ (upper figure). Vertical bars represent SEM. $n=4$

\section{b) Time Course of the Effect of Cholera Toxin}

A study of the time course of the cholera toxin effect was performed using $1 \mu \mathrm{g} / \mathrm{ml}$ cholera toxin in the presence of either $2.8 \mathrm{mM}$ or $16.7 \mathrm{mM}$ glucose. The results are shown in Fig. 2. In the presence of $16.7 \mathrm{mM}$ glucose cholera toxin induced a rapid and powerful stimulation of insulin release which was evident at $30 \mathrm{~min}$. At $1 \mathrm{~h}$ the insulin release stimulated by cholera toxin was 4 times greater than the insulin release due to high glucose alone. Subsequently, from $1-4 \mathrm{hrs}$, the rate of release was similar to that of high glucose. In the presence of low glucose insulin release was en- 
hanced and significantly elevated values were seen as early as $15 \mathrm{~min}$ after addition of the toxin $(p<0.005)$.

\section{c) Effect of a Short Period of Cholera Toxin Exposure}

Three paired experiments were performed in which $1 \mu \mathrm{g} / \mathrm{ml}$ cholera toxin was added to the incubation medium for only $2 \mathrm{~min}$. After the $2 \mathrm{~min}$ exposure the incubation medium was poured off and the culture dishes washed with fresh medium three times. After replacing the incubation medium insulin release was measured over the following four hours. Despite the short exposure time, insulin release was markedly stimulated relative to the $16.7 \mathrm{mM}$ glucose controls (see Table 1).

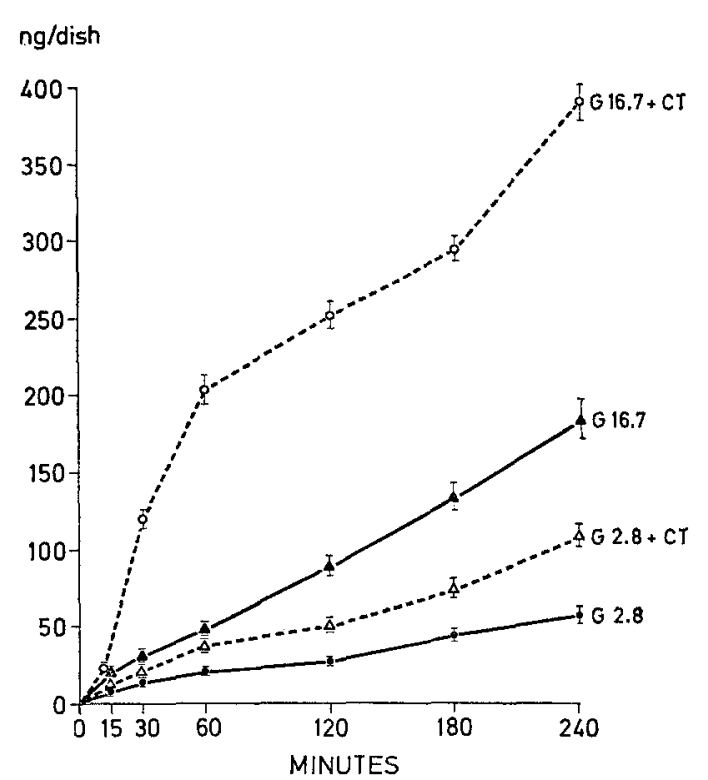

Fig. 2. Time course of the effect of cholera toxin $(1 \mu \mathrm{g} / \mathrm{ml})$ on insulin release in the presence of glucose at $2.8 \mathrm{mM}$ and at $16.7 \mathrm{mM}$. Vertical bars represent SEM. $\mathrm{n}=7$

Table 1. Effect of cholera toxin (1 $\mathrm{\mu g} / \mathrm{ml})$ on insulin release after only 2 min exposure of the cultured cells to the toxin. Insulin release measured at 4 hrs. All cultures in $16.7 \mathrm{mM}$ glucose

\begin{tabular}{lccr}
\hline Expt. & \multicolumn{2}{c}{ Insulin release ng/dish/4 hrs } & \multicolumn{1}{c}{$\Delta$} \\
\cline { 2 - 4 } & Control & Cholera toxin & \\
\hline 1 & 48.8 & 152.5 & 103.7 \\
2 & 78.8 & 162.5 & 83.7 \\
3 & 105.0 & 230.0 & 125.0 \\
\hline
\end{tabular}

\section{d) Effect of Cholera Toxin on Arginine Stimulated In- sulin Release}

Four series of experiments were performed. All media contained $2.8 \mathrm{mM}$ glucose. One series had only glucose, one had $1 \mu \mathrm{g} / \mathrm{ml}$ cholera toxin, one $10 \mathrm{mM}$ arginine hydrochloride and one the combination of arginine hydrochloride and cholera toxin. Insulin release was measured at intervals over $2 \mathrm{hrs}$. The results are shown in Fig. 3. As seen previously, cholera toxin increased insulin release slightly in the presence of $2.8 \mathrm{mM}$ glucose, although the increase failed to reach statistical significance at any time point. Arginine stimulated insulin release significantly from $15 \mathrm{~min}$ to $2 \mathrm{hrs}$ and the effect was greatly enhanced by cholera toxin. Between 30 and 60 min the rate of insulin release was four times greater in the presence of cholera toxin than with arginine alone. The release rate remained elevated between 1 and $2 \mathrm{hrs}$. Thus the insulin release due to arginine, as well as high glucose, was enhanced by cholera toxin, and in a similar manner.

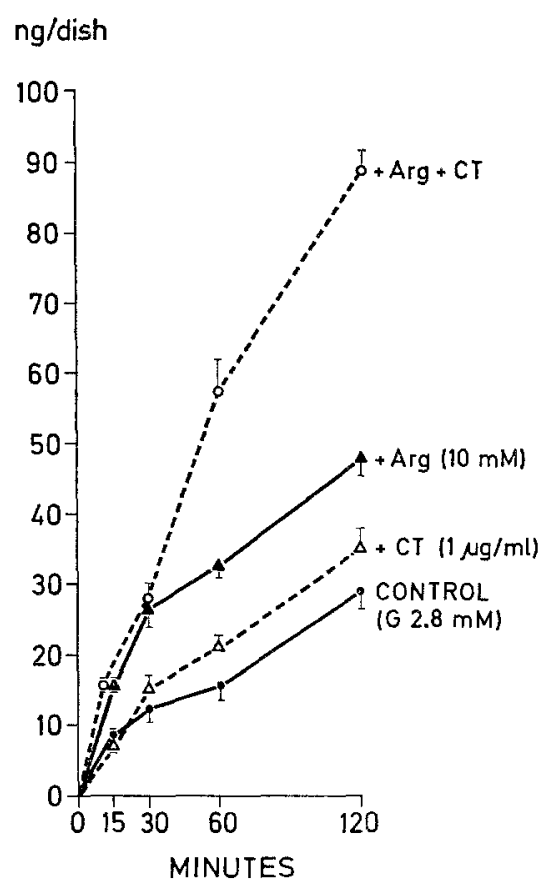

Fig. 3. Effect of cholera toxin on arginine-induced insulin release in the presence of $2.8 \mathrm{mM}$ glucose. Vertical bars represent SEM. $\mathrm{n}=6$

\section{e) Effect of Epinephrine on Glucose- and Cholera Toxin Stimulated Insulin Release}

Two series of experiments were performed in the presence of $16.7 \mathrm{mM}$ glucose. Both sets of culture dishes were incubated with $1 \mathrm{\mu g} / \mathrm{ml}$ cholera toxin for two hours and insulin release measured. At $2 \mathrm{~h}$ the solutions were changed and $2.7 \times 10^{-6} \mathrm{M}$ epinephrine added to the medium of the test cultures. After a further $2 \mathrm{~h}$ incubation in $16.7 \mathrm{mM}$ glucose, the insulin release was again measured. From the results in Table 2 it can be seen that cholera toxin and glucose elicited high rates of insulin release during the initial $2 \mathrm{~h}$. In the absence of epinephrine a high rate of release was maintained for the second $2 \mathrm{~h}$ period. In the presence of epinephrine, however, the rate of release was reduced to low levels. Thus epinephrine exerted its characteristic inhibitory effect on insulin release even in the presence of cholera toxin. 
Table 2. Effect of epinephrine (2.7 $\mu M$ ) on insulin release induced by cholera toxin $(1 \mu \mathrm{g} / \mathrm{ml})$ in the presence of 16.7 $m M$ glucose. Insulin release measured over 2 hrs in the absence of epinephrine, and then, after changing the inoubation medium, in the presence and absence of epinephrine

\begin{tabular}{|c|c|c|c|}
\hline & $\begin{array}{l}\text { Insulin release } \\
1 \text { st } 2 \mathrm{~h} \text { period } \\
\text { ng/dish }\end{array}$ & & $\begin{array}{l}\text { Insulin release } \\
\text { 2nd } 2 \mathrm{~h} \text { period } \\
\text { ng/dish }\end{array}$ \\
\hline $\begin{array}{l}\text { Con- } \\
\text { trol }\end{array}$ & $78.3 \pm 5.5$ & Medium changed & $69.2 \pm 2.6$ \\
\hline Test & $81.5 \pm 7.2$ & $\begin{array}{l}\text { Medium changed } \\
\text { and epinephrine } \\
\text { added }\end{array}$ & $10.2 \pm 2.3$ \\
\hline $\begin{array}{l}\Delta \\
P \\
\mathrm{n}\end{array}$ & $\begin{aligned} & 3.2 \pm 9.9 \\
&< 0.8 \\
& 6\end{aligned}$ & & $\begin{array}{l}59.0 \pm 2.3 \\
<0.001 \\
6\end{array}$ \\
\hline
\end{tabular}

f) Relative Effects of Cholera Toxin, Cyclic AMP, Theophylline and Glucagon on the Rate of Insulin Release in the Presence of $16.7 \mathrm{mM}$ Glucose

The results of these experiments are shown in Fig. 4. Cyclic AMP, theophylline and glucagon, all in the presence of $16.7 \mathrm{mM}$ glucose, produced a rapid increase in insulin release relative to high glucose alone, during the first $30 \mathrm{~min}$ of incubation. With the exception of glucagon, subsequent rates with these agents were not significantly greater than that achieved with high glucose alone.

\section{Discussion}

Cholera toxin has been shown to stimulate adenylate cyclase and to elevate intracellular cyclic AMP concentrations in many cell types [3-12]. The effect is essentially irreversible and can be produced by brief application of the toxin to the cells. All the effects reported thus far for the purified toxin can be explained by a stimulation of the membrane bound adenylate cyclase. Thus the toxin can be used to mimic physiological responses due to increased cyclic AMP levels.

In the experiments reported here, cholera toxin reproduces the effects of cyclic AMP, and agents which enhance cyclic AMP accumulation, on the rate of insulin release by the B-cell. The toxin enhances insulin release at concentrations of $10^{-10}-10^{-8} \mathrm{M}$, although it should be noted that this is an operational definition as cholera toxin binds to cell membranes it is taken out of the bathing medium. Thus, particularly at low concentrations, the amount of toxin available as well as its concentration will determine the magnitude of the subsequent response. The enhanced release can be apparent as early as 15 min after addition of the toxin to the cells, although full development of the enhancement occurred between 30 and $60 \mathrm{~min}$. This latent period before onset of action is in accord with results in other tissues, but is in contrast to the effects of glu-

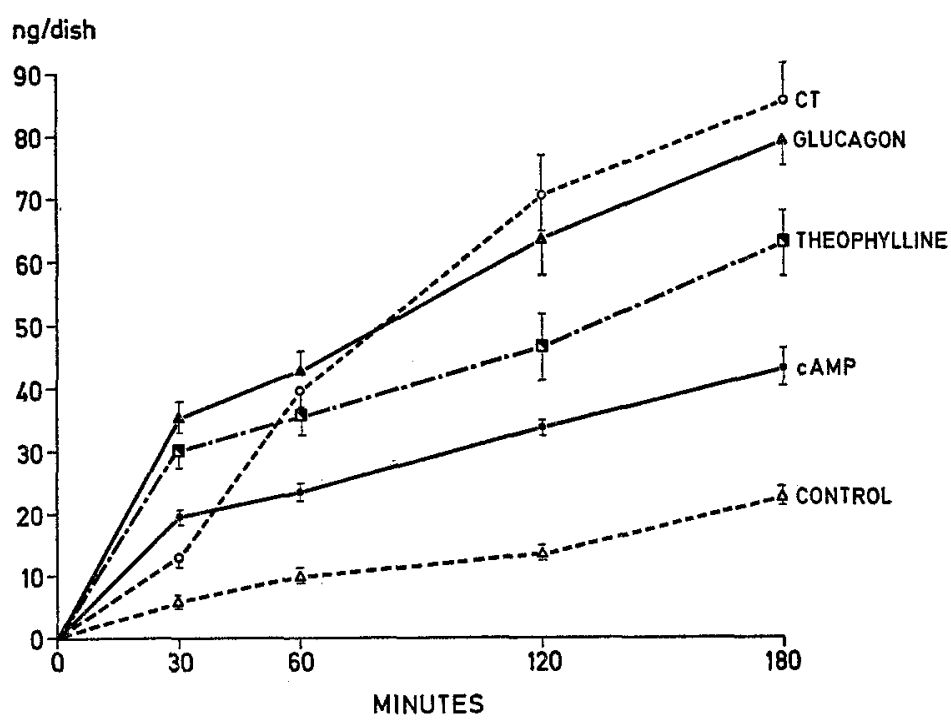

Fig. 4. Relative effects of $1 \mu \mathrm{g} / \mathrm{ml}$ cholera toxin, $1.5 \mu \mathrm{M}$ glucagon, $10 \mathrm{mM}$ cyclic AMP (all $\mathrm{n}=6$ ) and $5 \mathrm{mM}$ theophylline $(n=5)$ on insulin release induced by $16.7 \mathrm{mM}$ glucose. Vertical bars represent SEM

Cholera toxin significantly increased insulin release during the first $30 \mathrm{~min}(p<0.01)$, but the release was significantly less than that caused by the other agents in combination with glucose. Between 30 and $60 \mathrm{~min}$, however, cholera toxin accelerated the rate of insulin release to high levels and at $2 \mathrm{~h}$ the amount of insulin released was significantly greater than that of the other groups ( $p<0.001$ with respect to cyclic AMP, $p<0.005$ for theophylline and $p<0.05$ for glucagon). cagon, theophylline and exogenous cyclic AMP, which cause a prompt rise in intracellular cyclic AMP levels and insulin release. Also in contrast to these agents is the fact that only a $2 \mathrm{~min}$ application of the toxin (followed by washing) is required for the subsequent development of a large stimulatory effect. In its ability to stimulate insulin release from the B-cell, cholera toxin was comparable to glucagon, theophylline or exogenous cyclic AMP. Moreover, like these sub- 
stances, cholera toxin was more effective in eliciting insulin release at high than low glucose concentrations. Thus, at $2.8 \mathrm{mM}$ glucose cholera toxin stimulated release only in one series of experiments (Fig. 2) and failed to do so in two other series (Fig. 1 b) and 3). This might be due to a threshold phenomenon. The threshold concentrations of glucose at which, for instance, theophylline is effective in some pancreatic prepara. tions has been reported to be $2.8 \mathrm{mM}[15,18]$. Insulin release induced by arginine, as well as glucose, could be enhanced by cholera toxin in agreement with the known effects of cyclic AMP on B-cell function. Epinephrine, a potent inhibitor of insulin release, exerted its usual inhibitory effect even in the presence of the toxin. As epinephrine inhibits the effects of exogenous cyclic AMP and theophylline on insulin release [22], this again is in accord with the anticipated behaviour of the toxin-stimulated B-cell.

In conclusion, cholera toxin stimulates insulin release in a manner similar to other agents that increase intracellular cyclic AMP levels, such as glucagon or theophylline. The effect is large and sustained and cholera toxin should be a useful tool for the study of cyclic AMP-induced enhancement of insulin release.

Acknowledgements. The authors are grateful to Mrs. Theres Cuche, Mrs. Pascale Demay and Mrs. Marie-Paule Barrillat for their skilled technical assistance.

This work was supported by the Fonds National Suisse de la Recherche Scientifique (Grants Nos. 3.384.70, $3.1060 .73,3.541 .71$ and 3.0280.73), and the Roche Research Foundation for Scientific Exchange and Biomedical Collaboration with Switzerland.

\section{References}

1. De, S.N.: Enterotoxicity of bacteria-free culture filtrate of Vibriocholerae. Nature (Lond) 183, 15331534 (1959)

2. LoSpalluto, J.J., Finkelstein, R.A.: Chemical and physical properties of cholera exo-enterotoxin (choleragen) and its spontaneously formed toxoid (choleragenoid). Biochim. biophys. Acta. (Amst.) 257, 158-166 (1972)

3. Field, M.: Intestinal secretion : Effect of cyclic AMP and its role in cholera. New England J. Med. 284, $1137-1144$ (1971)

4. Sharp, G.W.G., Hymie, S.: Stimulation of intestinal adenyl cyclase by cholera toxin. Nature (Lond) 229, $266-269(1971)$

5. Kimberg, D. V., Field, M., Johnson, J., Henderson, A., Gershon, E.: Stimulation of intestinal mucosal adenyl cyclase by cholera enterotoxin and prostaglandins. J. clin. Invest. 50, 1218-1230 (1971)

6. Chen, L.C., Rohde, J.E., Sharp, G.W.G.: Properties of adenyl-cyclase from human jejunal mucosa during naturally acquired cholera and convalescence. J. clin. Invest. 51, $731-740(1972)$

7. Vaughan, M., Pierce, N.F., Greenough, W.B.: Stimulation of glycerol production in fat cells by cholera toxin. Nature (Lond) 226, 658-659 (1970)
8. Zieve, P.D., Pierce, N.F., Greenough, W.B.: Stimulation of glycogenolysis by purified cholera exotoxin in disrupted cells. Johns Hopk. med. J. 129, 299-303 (1971)

9. Beckman, B., Flores, J., Witkum, P.A., Sharp, G.W. G.: Studies on the mode of action of cholera toxin: Effects on solubilized adenylate cyclase. J. clin. Invest. 53, 1202-1205 (1974)

10. Bourne, H.R.; Lehrer, R.I., Lichtenstein, L.M., Weissman, G., Zurier, R.: Effects of cholera enterotoxin on adenosine $3^{\prime}-5^{\prime}$ monophosphate and neutrophil function. J. clin. Invest. 52, 698-708 (1973)

11. Wolff, J., Temple, R., Hope Cook, G.: Stimulation of steroid secretion in adrenal tumor cells by choleragen. Proc. nat. Acad. Sci. (Wash.) 70, 2741 - 2744 (1973)

12. Donta, S.T., King, M., Sloper, K.: Induction of steroidogenesis in tissue culture by cholera enterotoxin. Nature New Biol. 243, 246-247 (1973)

13. Sussman, K.E., Vaughan, G.D.: Insulin release after ACTH, glucagon and adenosine $\mathbf{3}^{\prime}, \mathbf{5}^{\prime}$-phosphate (cyclic AMP) in the perfused isolated rat pancreas. Diabetes 16, $449-454$ (1967)

14. Malaisse, W.J., Malaisse-Lagae, F., Mayhew, D.: A possible role for the adenyl cyclase system in insulin secretion. J. clin. Invest. 46, 1724-1734 (1967)

15. Lambert, A.E., Kanazawa, Y., Burr, I.M., Orci, L., Renold, A.E.: On the role of cyclic AMP in insulin release. I : Overall effects in cultured fetal rat pancreas. Ann. N.Y. Acad. Sci. 185, 232-244 (1971)

16. Basabe, J.C., Lopoz, N. L., Viktora, J.K., Wolff, F. W.: Insulin secretion studies in the perfused rat pancreas. II. Effect of glucose, glucagon $3^{\prime}, 5^{\prime}$-adenosine monophosphate, theophylline, imidazole, and phenoxybenzamine. Their interaction with diazoxide. Diabetes 20, 457-466 (1971)

17. Lambert, A.E., Blondel, B., Kanazawa, Y., Orci, L., Renold, A. E.: Monolayer cell culture of neonatal rat pancreas: Light microscopy and evidence for immunoreactive insulin synthesis and release. Endocrinology 90, 239-248 (1972)

18. Marliss, E.B., Wollheim, C.B., Blondel, B., Orci, L., Lambert, A.E., Stauffacher, W., Like, A.A., Renold, A.E.: Insulin and glucagon release from monolayer cell cultures of pancreas from newborn rats. Europ. J. clin. Invest. $3,16-26(1973)$

19. Orci, L., Like, A.A., Amherdt, M., Blondel, B., Kanazawa, Y., Marliss, E.B., Lambert, A.E., Wollheim, C.B., Renold, A.E.: Monolayer cell culture of neonatal rat pancreas: an ultrastructural and biochemical study of functioning endocrine cells. Ultrastr. Res. 43, 270-297 (1973)

20. Herbert, V., Lau, K.-S., Gottlieb, C.W., Bleicher, S. J.: Coated charcoal immunoassay of insulin. J. clin. Endocr. 25, 1375-1384 (1965)

21. Finkelstein, R.A., Lo Spalluto, J.J.: Production of highly purified choleragen and choleragenoid. J. infect. Dis. 121 (Suppl.) s 63 (1970)

22. Malaisse, W.J., Brisson, G., Malaisse-Lagae, F.: The stimulus-secretion coupling of glucose-induced insulin release. I. Interaction of epinephrine and alkaline earth cations. J. Lab. clin. Med. 76, 895-902 (1970)

C. Wollheim, M.D.

University of Geneva

Institut de Biochimie Clinique

Sentier de la Roseraie

$\mathrm{CH}-1211$ Geneva 4

Switzerland 